\title{
Web Accessibility Challenges
}

\author{
${ }^{1}$ Hayfa.Y.Abuaddous, ${ }^{2}$ Mohd Zalisham Jali, ${ }^{3}$ Nurlida Basir \\ ${ }^{1,2 \& 3}$ Faculty of Science \& Technology, Universiti Sains Islam Malaysia (USIM) \\ 71800, Nilai, Negeri Sembilan, Malaysia
}

\begin{abstract}
Despite the importance of web accessibility in recent years, websites remain partially or completely inaccessible to certain sectors of the population. This is due to several reasons, including web developers' little or no experience in accessibility and the lack of accurate information about the best ways to quickly and easily identify accessibility problems using different Accessibility Evaluation Methods (AEMs). This paper surveys accessibility literature and presents a general overview of the primary challenges of accessibility barriers on websites. In this sense, we critically investigate main challenges forms related to accessibility including standards and guidelines (WCAG 2.0), during website's design and development and during evaluation. Finally, a set of recommendations such as enforcing accessibility legislations are presented to overcome some challenges.
\end{abstract}

Keywords-component; Website Accessibility; Disabilities; Accessibility challenges; WCAG 2.0; Accessibility automated tools

\section{INTRODUCTION}

The use of the Internet has been rapidly spreading to most areas of human life. In many industrialized countries, electronic or mobile governmental services are provided in almost all sectors such as immigration, education, commerce, news, workplace interaction, health care, recreation, and entertainment. This would enable citizens and residents to easily and efficiently access different services without usual problems, i.e. long queues, much time and effort. However, it is imperative to provide accessible web services to the majority of people including those with certain disabilities (permanent or temporary) so as to secure equal access and opportunities for everybody.

We can define "web accessibility" as making a website navigable and tractable by various user categories especially those who have disabilities and normally face obstacles when interacting with the web via electronic devices (e.g. blindness). Web accessibility entails overcoming most disabilities that limit Internet access. It means that people with disabilities can use, perceive, understand, navigate, and interact with the web [1]. According to World Wide Web Consortium [2], web accessibility enables people with disabilities, i.e. blind, aged, to utilize the Internet in performing variety of tasks such as online purchasing and browsing. As more accessible websites and software become available, people with disabilities are able to use and contribute to the Web more effectively.

Despite the importance of web accessibility as a research topic, the majority of websites developed remain inaccessible or semi-accessible $[3,4]$. This is due to reasons to be discussed in Section II. In addition, web accessibility faces several challenges such as resource allocation, established managerial practices, and time limitation [5]. As a matter of fact, new research findings $[6,7,8]$ suggest an imminent need to look beyond the "how to" question of designing websites in order to consider accessibility constraints, accessibility context and the role of professionals who normally are involved in website development, e.g. web designers, web developers, and quality assurance engineers. This will make websites more accessible to different types of Internet users. The following is a list of challenges related to web accessibility in developing countries adopted from $[8,9,10,11]$ :

- Lack of accessibility awareness when designing and implementing websites.

- Limited resources allocated to cover accessibility issues, both tangible and intangible, issues.

- Scarcity of professionals who are familiar with accessibility evaluation tools.

- Dearth of appropriate structured accessibility manuals for web developers and unavailability of web accessibility training courses.

These and some other challenges, like lack of motivation among web developers, contribute to making websites inaccessible for the disabled. Furthermore, lack of efficiency among novices (inexperienced) in the evaluation process may impact web accessibility [12, 13], and web designers and developers may lack the necessary knowledge to implement techniques that support accessibility. All these problems contribute to the existence of several barriers in web accessibility and stimulate interest in this research domain to investigate more the "why" question: "Despite the availability of different resources, why are the majority of online websites still inaccessible?"

This paper critically contrasts various web accessibility challenges raised by current scholars in the last decade. For this purpose, we categorize challenges related to web accessibility using our own taxonomy to stand out from the others, as depicted in Fig.1. 


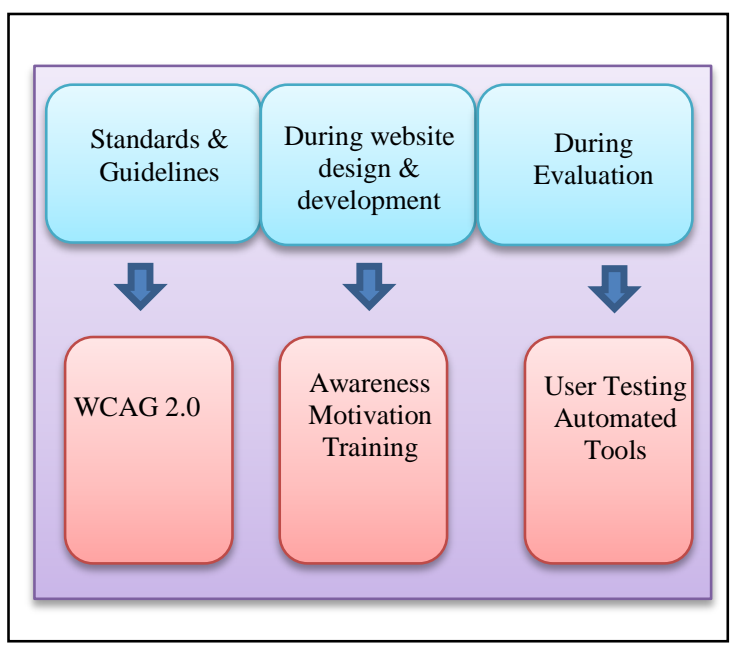

Fig. 1. Web accessibility challenges categories

In fact, many research studies on accessibility have been conducted to evaluate the accessibility conditions of public websites $[14,15,16,17]$. Nevertheless, few of these studies critically analyzed accessibility challenges $[18,19]$. Therefore, this article stresses the vital role of web accessibility not only for disabled Internet users but also for websites developers as well as IT team in charge of building and maintaining websites. We believe that web accessibility is directly related to an organization's profit, legislation, and image within society. It can be seen as a way for an organization to demonstrate its commitment to provide equal opportunities to all users. This can also be seen as a sort of corporate social responsibility. A major benefit of web accessibility for organizations is the potential direct and indirect financial gains from increased access to their websites.

The paper's structure goes as follows: web accessibility challenges section is split into three subsections: the first subsection is devoted to discuss challenges regarding standards and guidelines; second subsection demonstrates various web accessibility challenges during website's design and development and third subsection focuses on common accessibility difficulties faced by website makers (designers, developers) during the process of website evaluation. Recommendations and solutions to handle challenges are discussed in Section III. Section IV summarizes the challenges and Section V concludes this paper.

\section{WeB ACCESSIBILITY CHALLENGES}

This section is divided into three subsections related to web accessibility challenges:

- Standards and Guidelines.

- During website's design and development.

- During accessibility evaluation.

Website accessibility barriers resulted from the evaluation of a website are discussed based on our own classification of challenges. In particular, we survey the above challenges and evaluate their impact on the accessibility of the website or the users' ability to interact with its content.

\section{A. Challenges related to accessibility standards and guidelines}

The increasing number of national laws and policies addressing the accessibility of information and communication technologies (ICT), including the web, resulted in many different approaches in practice. Some of the laws and policies are based on establishing a human right to ICT. Many adhere to the approach in which any ICT purchased by government must be accessible, while others believe that any ICT sold in a given market must be accessible, among other approaches [20]. While many countries such as France and Spain have developed their own accessibility legislations, some developing countries still do not have a specific item of legislation protecting the rights of people with disabilities [21]. These rights are bound in a more general equality act and differ in the level of definition of disabilities and in successfully accessing and using digital content, products and services. Besides the mandatory accessibility legislations enforced by many countries, many voluntary standards and guidelines were founded to support social inclusion of disabled people.

While W3C's Web Content Accessibility Guidelines (WCAG) is the most internationally adopted voluntary web accessibility standard [22], many other guidelines and standards were established as well (e.g. Section 508, BITV, Fujitsu). Furthermore, there is sometimes one version of a guideline or standard at the national level, different versions at the provincial or state level, and yet different versions adopted by commercial, educational, and non-governmental organizations within the same country. This section focuses on WCAG 2.0 since it has been lately the most widely used web standard in the literature [23, 24, 25, 26].

The World Wide Web Consortium [27] is an international consortium that aims to develop web standards. Its mission is pursued through making general guidelines that will lead to web standards. W3C's Web Accessibility Initiative (WAI), which is part of the W3C, focuses on enabling people with disabilities to create and interact with web content. WAI promotes: a) the implementation of web accessibility guidelines in advanced tools, and b) the improvement of accessibility evaluation tools [28]. Together, these may increase the number of disabled people who use the internet.

The WAI has developed: 1) Web Content Accessibility Guidelines (WCAG) which describe how to make Web content and Web sites accessible, 2) Authoring Tool Accessibility Guidelines (ATAG) for the web authoring tools used to create the content, and 3) User Agent Accessibility Guidelines (UAAG) for the tools used to access that content (e.g. browsers and media players). Despite the importance of ATAG and UAAG, we will concentrate on WCAG challenges for two reasons: first, there is enough literature about the WCAG that can allow us to critically analyze it. Second, many automated tools that have been developed to perform website evaluation are using rules/criteria presented within WCAG guidelines. Within WAI, the WCAG documents (WCAG 1.0 and WCAG 2.0) were developed. The WCAG 1.0 was published and became a W3C recommendation in 1999 and was then superseded by WCAG 2.0 in 2008. Although it is possible to conform either to WCAG 1.0 or to WCAG 2.0 (or both), the 
W3C recommends the use of WCAG 2.0 for new and updated content.

WCAG 2.0 is organized around four design principles that provide the foundation for web accessibility (perceivable, operable, understandable, and robust) [29]. Under these principles there are 12 guidelines. Each guideline has one or more testable success criteria (SCs). There are $61 \mathrm{SCs}$ at levels A (lowest), AA (medium), and AAA (highest). In WCAG 2.0, a single issue can be covered by more than one $\mathrm{SC}$ at different priority levels [29]. Table I demonstrates the WCAG 2.0 conformance levels as classified by [29].

TABLE I. WCAG 2.0 CONFORMANCE LEVELS

\begin{tabular}{|c|c|c|c|}
\hline $\begin{array}{l}\text { Conformance } \\
\text { Level }\end{array}$ & $\mathbf{A}$ & $\mathbf{A A}$ & AAA \\
\hline Explanation & $\begin{array}{l}\quad \text { All SCs } \\
\text { of level A are } \\
\text { satisfied. } \\
\text { This is the } \\
\text { "minimum } \\
\text { standard" } \\
\text { which a } \\
\text { website must } \\
\text { meet to be } \\
\text { considered } \\
\text { accessible for } \\
\text { any } \\
\text { significant } \\
\text { disability } \\
\text { groups. }\end{array}$ & $\begin{array}{l}\quad \text { All SCs of } \\
\text { Level A and AA } \\
\text { are satisfied. } \\
\text { This is a } \\
\text { "professional } \\
\text { practice } \\
\text { standard", which } \\
\text { a website should } \\
\text { meet to be } \\
\text { accessible to a } \\
\text { broad range of } \\
\text { disability } \\
\text { groups. }\end{array}$ & $\begin{array}{l}\quad \text { All SCs (at all } \\
\text { conformance } \\
\text { levels) are } \\
\text { satisfied. This is a } \\
\text { "gold standard" of } \\
\text { maximum } \\
\text { accessibility which } \\
\text { some websites may } \\
\text { choose. }\end{array}$ \\
\hline
\end{tabular}

In order to prevent the obsolescence of WCAG against the fast evolution of technology, the WAI removed the technical aspects of accessibility from their guidelines and SC. Technical information regarding how to implement web content with existing web technologies is now provided in separate documents. However, in spite of all of these changes, recent studies $[7,30]$ have shown that many of the problems raised in WCAG 1.0 still persist in WCAG 2.0 and there have been little improvement in the level of web accessibility.

Although WAI pursues its mission through the creation of guidelines, these do not guarantee accessibility [31]. There is still a lack of empirical evidence to demonstrate that conformance to WCAG 2.0 leads to more accessible websites for disabled users. A study conducted by [7] showed that conformance of a website to WCAG 2.0 Level A does not mean that disabled users will encounter fewer problems.

Many issues have been raised about WCAG 2.0, such as the level of understanding of accessibility issues required when using them [32, 33]. One common challenge that is usually faced by web developers is their inability to interpret or understand guidelines to enable accessibility. WCAG 2.0 documents are not easy to understand and require a certain level of technical knowledge of accessibility. Therefore, when developers or designers are required to implement accessibility, they do not always understand how to achieve the desired requirements. Alonso et al. [34] showed that a group of 25 novice evaluators struggled to consistently rate problems according to WCAG 2.0. One cause of this was in the interpretation of the guidelines and the SCs. Besides the manual verification is needed by evaluators and web developers, guidelines-based accessibility evaluation has several disadvantages [35]. WCAG 2.0 documents are difficult to navigate and locate. All the documents related to this Guideline exceed 450 pages with few hundred navigation links on each single page. Moreover, WCAG 2.0 tends to create supporting documents that can be updated more regularly than the standard itself, which can be a burden to web developers since exploring these updates, necessitates both time and effort. As such, WCAG 2.0 could be unusable by real-world developers. In addition, WCAG 2.0 development itself is inaccessible to anyone who does not understand English.

Loitsch et al. [36] pointed out that there exist ambiguities in the language used in WCAG 2.0. For instance, WCAG 2.0 stated that all "the success criteria (SCs) are testable when people who understand WCAG 2.0 test the same content using the same SCs, the same results should be obtained with high inter-rater reliability". However, no explanations were provided about the minimum number of testers needed to fulfill the required "high inter-rater reliability"; also, the level of agreement between evaluators is undefined. Should all the testers obtain the same results or a certain portion of them is enough? Furthermore, [36] mentioned the need for people who understand WCAG 2.0 tests without clarifying the level of expertise needed. This can lead to many different interpretations of what is required. This ambiguity could affect the efficiency and the effectiveness of the evaluation process. Eventually, this may create a gap between evaluators and the evaluation process.

Petrie et al. [37] conducted interviews with 14 web accessibility evaluators. They found that they were unclear on the differences between automated and manual testing of accessibility and what can be tested through the automated tools. In addition, [38] had 22 expert and 27 non-expert evaluators to perform accessibility evaluation using WCAG 2.0 and discovered that $50 \%$ of testers were unable to come to an $80 \%$ level of agreement about whether a problem was present in a webpage. Additionally, when using WCAG $2.020 \%$ of the problems reported by the evaluators were false positives and $32 \%$ of the true accessibility problems had been missed. A false positive occurs if the violation has not taken place and was reported, whereas a false negative occurs if the violation really has taken place and was not reported. For the nonexperts, the results were even worse having higher levels of false positives.

The focus of WCAG 2.0 is on the technical artifact, e.g. the webpage - not on users and their goals. This means that the activity of WCAG conformance is oriented towards testing these technical artifacts against SCs - rather than evaluating the user experience with specific impairments trying to complete specific tasks. Although a technical testing's focus can be helpful for programmers treating accessibility evaluation as a bug-fixing activity, this level of technical focus inevitably creates a gap between accessibility and user experience for disabled people [30]. Of a greater concern is WCAG 2.0's emphasis on perfect score on all SCs for a level to get the level conformance logo, which makes it impossible for some websites to achieve any acceptable level of conformance. WAI ignored the fact that in website development process, 
developers do not seek perfection; instead, they aim for a continuous, pragmatic improvement over versions [39].

\section{B. Challenges during website's design and development}

Many challenges face the staff developing websites before testing and evaluating accessibility, mainly lack of awareness and motivation and the scarcity of professional training courses that may handle accessibility issues. Developing websites requires a team effort that includes developers, designers, content producers and project manager. For the web community, each member of this team has certain responsibilities related to his skills in delivering an accessible website. However, it is the project manager who monitors high-level adherence to business goals, and without his support, there will not be any changes to accessibility unless governments truly start enforcing legislation. Without a managerial impact on accessibility, it is quite normal for a web team to ignore this accessibility issue or pretend they have taken care of it [40]. A project manager should ensure the early engagement of his team in the accessibility process. He should motivate and encourage the web team to get involved in the accessibility issues at early stages. Project managers are responsible for showing the importance of web accessibility to their teams as well as the positive effect of web accessibility on the commercial and community levels. If none of the project members is experienced in accessibility, then a third party can be consulted or out-sourced to perform this task. Lack of accessibility may result in the marginalization of certain user groups, preventing them from accessing the website.

In this section we discuss the main challenges faced in projects related to accessible website during the design and the development of a website. Initially, we highlight the accessibility awareness and motivation among the project's members especially IT developers. Then, we focus on the benefits of web accessibility training for web development staff.

\section{1) Lack of accessibility awareness and motivation}

Challenges such as lack of awareness are very common among web developers, besides motivation, knowledge and guidance. The latter challenges are faced by most novice evaluators. Whether facing experienced web developers or novice evaluators, all challenges contribute to the continuing presence of accessibility barriers on websites.

There are moral, legal and economic arguments for implementing accessible websites promoted by advocacy organizations such as disability related charities and academic organizations [41]. Nevertheless, few web designers follow accessibility guidelines [42]. Although the WAI of the W3C have published online guidelines, most IT professionals are unaware of them, and companies that have government contracts are mandated by their government's legislation to make their websites accessible [8]. The low level of accessibility is likely to be the result of several factors. For instance, despite the increase on awareness pertaining to accessibility over the last few years at the level of government and legislation, web designers' knowledge remains quite low [7].
Pye [43] tested the importance of accessibility awareness for IT professionals and its effect on the accessibility level for visually disabled users. The author used a questionnaire and interviewed members of charity organizations that concern themselves with the matters of web accessibility for visually disabled persons. The results of the study revealed that there are certain rules to increase awareness of all individuals involved in web development. Country-specific legislation should be introduced in web accessibility. There is also a key requirement for the continuation of the other current enforcement methods, such as assistive technology, to overcome the accessibility barriers. However, no precise recommendations are given by the author to treat the highlighted awareness problem.

In the USA, [41] showed the lack of awareness in public libraries. These libraries usually do not consider community members with physical disabilities when designing their websites. Therefore, the findings suggested that public library websites are not suited to deliver effective information services for users who need special assistance. Furthermore, this study revealed that public libraries do not consider having an appropriate funding in their reserved budget to support accessibility.

In the research conducted by [3], 20 websites of Finnish higher education's institutes have been examined to evaluate their web accessibility by an application software named TAW [44]. The results showed that $30 \%$ of tested websites have full automatic accessibility in priority ' $A$ ' level but none of the tested websites has 'AA' compliance. Most of the tested websites have low accessibility issues. The author claims that the lack of accessibility awareness among developers is the main reason.

Until now, the majority of IT professionals, especially those who are involved in developing websites, are not motivated to learn more about accessibility. This is because they do not have a comprehensive knowledge of accessibility and the difference it makes to disabled users and community commercial organizations [24]. So, the challenge is to increase the level of awareness of the IT web team regarding the impact and rewards of web accessibility as well as to motivate them through course training that highlights these rewards and benefits [10]. On the other side, the lack of motivation does not necessarily mean lack of awareness since many IT professionals are aware of web accessibility legislations but not motivated to follow them.

Rosson et al. [45] conducted a survey involving 334 web developers. The aim was to understand the needs, problems and the processes that developers follow and the tools they use in websites development. During website implementation, the authors have observed that while developers were quite conscious of the overall quality and usability issues, only 5\% of the respondents performed web accessibility testing. They hypothesized that this may be partly due to a lack of knowledge and motivation because of the relatively tedious and time-consuming testing required. Although [45] experiment was conducted 10 years ago, the motivation factor has remained an issue until now. One of the common justifications given by the developers to abandon accessibility 
according to [46] is the limited time or resources' incompatibility of technology to accomplish this task. This happens because the accessibility specialist is just a small cog in a big wheel or even there is no specialist at all in the organization.

Trewin et al. [5] surveyed IBM rich internet application developers with varying levels of accessibility expertise to explore two concerns: barriers faced by developers when designing accessible web-based products and the value gained from the accessibility test. The findings showed that even for developers with experience in web accessibility, testing has been seen the most time-consuming among other phases with relatively low impact on the website. Nahon et al. [4] reported obstacles and incentives for non-professional web makers (e.g. blog writers and/or creators of personal websites) to consider accessibility in their work. The authors presented a theoretical framework that described variables they hypothesized would contribute to designers' intention. They found that intrinsic motivation was the strongest predictor of a positive attitude that affected the intention to make technology accessible.

\section{2) Lack of training}

No one can deny that professional training, good education and guidance are crucial to produce skilled IT staff members who can understand the urgent need for accessibility. The lack of skilled staff may eventually negatively impact accessibility. However, accessibility training for web developers is still not available in most IT training centers. Thus, many web developers continue producing websites that are inaccessible.

Many developers claim that accessibility is difficult to accommodate. Part of the problem is a lack of exposure to accessibility during training [13, 25, 47]. Most web designers and developers have little or no experience to ensure that their code meets accessibility requirements. Designers approach accessibility problems differently than other IT professionals, such as Human Computer Interaction (HCI) specialists and developers. Designers and developers typically tend to think that web users are just like them [48].

Recently, developers have indicated a need for more education in accessibility. An exploratory study [49] on the current state of accessibility surveyed more than 400 developers throughout Europe. The study found that $85 \%$ of developers wanted more accessibility training with more information on disabilities and the use of assistive devices. Moreover, web testers need training in accessibility evaluation methods like conducting real user testing with blind users and using screening techniques besides assistive technologies. One Brazilian study [50] revealed that while $45 \%$ of web-related professionals were aware of screen readers for blind users, they did not know how to make webpages screen reader-compatible.

There are a great number of recommendations for accessible development, but these are often distant from the developers' way of programming. As a consequence, developers do not follow them [32, 50]. Avila et al. [6] stated that for web developers to create functionally accessible web resources, more than general guidelines and evaluation tools are required. Thus, it is recommended that more training be given to web development teams in order to raise their awareness and give them a better understanding of end-users.

\section{Challenges during evaluation}

Web accessibility evaluation methods have been widely studied, and different evaluation methods have been proposed, e.g. $[38,51]$. Different AEMs lead to different kinds of results and quality. They require different levels of resources and differ in their applicability [38]. These methods have contrasting pros and cons and various properties [52]. For example, they differ in many ways:

- Method of implementation (analytical or observational).

- Users performing the evaluation.

- Purpose of implementation.

- Methods used in obtaining results.

- Cost/resources spent in evaluation.

This section explores the main challenges in the accessibility evaluation process faced by IT staff when they test websites using an automated method. In the next subsection, we are going to cover challenges related to automated testing and user testing. Screening techniques and other assistive technologies problems are highlighted in subsection (2), since they are related to each another.

\section{1) Automated testing problems}

WCAG can be checked manually, though verifying a site's accessibility manually can be time-consuming. Thus, software developers have created a number of tools to simplify this process. Web accessibility testing tools are software programs and web based services that help in determining whether a website meets accessibility guidelines [38]. These tools can help reduce the time and effort required for the evaluation process. Testing normally involves an evaluator to check conformance of a webpage against the accessibility rules encoded in the tool. A-Checker [53], WAVE [54] and TAW [44] are examples of automated evaluation tools. Generally, expert users are required to follow up with the results derived by the tool to determine the rate of accessibility.

Common drawbacks of automatic accessibility tools have been highlighted by many scholars, e.g. $[1,25,47]$. There is not much information about the difficulties that evaluators may face when assessing accessibility using these tools [35]. However, one of the most known deficiencies of automated tools is the difficulty in interpreting results. At first glance, running evaluation using automated tools sounds easy. Unfortunately, they are time consuming when the novice web developers try to analyze their results. Moreover, interpreting these results requires an expert web developer with a technical background in web accessibility. This necessitates constant checking against manuals and documentations. When these tools are used by practitioners who lack experience or knowledge in accessibility, the results can be unpredictable and the quality of findings questionable.

There is high detection rate of defects among many of these evaluation tools, which necessitates a user's manual inspection and, thus, resources are wasted [55]. Automated tools are normally broad in that they apply specific accessibility standards or guidelines and produce a list of automatically 
detected problems [47]. Automated testing covers only a small proportion of WCAG 2.0 and is unable to check every aspect of accessibility [56], but they are possibly able to flag items that need to be manually checked. It has been estimated that more than half of the provisions in most accessibility standards ask for human judgment during evaluation process. Some tools like TAW do not evaluate the web content using all guidelines criteria and the rest are usually evaluated by testers who are commonly left to their own interpretation of those guidelines [6].

Trewin et al. [5] interviewed 49 IBM web developers and revealed that the majority of the existing evaluation tools are often unclear, cumbersome and incomplete with respect to standards or guidelines that must be met. Moreover, some automated testing tools do not provide support for changed or newly developed accessibility guidelines. While tools can check the adherence to a number of guidelines, some guidelines are not checked properly. For example, it is hard for tools to ascertain whether the "alt" attribute is meaningful or not. This can result in high false positive and inaccurate results. Inaccurate results can decrease the efficiency and increase the cost of accessibility testing. Trewin et al. [5] showed a need for new methodologies, particularly mixed ones, that may reduce false positive results. Precisely, to ease end-user interpretability, light-weight visualizations that support novices in performing manual checks and simplification of the automated tools' results are needed. The research community of accessibility is still unable to standardize ways or methods that are fully automated to generate accessibility rate for a specific website. Developers of interactive systems, especially websites, are frequently not specialists in accessibility and usability techniques. In the absence of an accessibility expert, the evaluation tool might go a long way to find adherence to the standard guideline. But even hiring an accessibility expert may often be beyond the financial capabilities of a typical website development project.

Two experiments were conducted in 2012 and 2013 by [57] using the following tools: Accessibility Check, A-Checker and TAW [44] for 20 public universities in Malaysia in order to diagnose the overall accessibility of these universities' websites. Unfortunately, none of the websites were fully accessible based on the results obtained by the selected tools. In addition, the results obtained varied and were expressed in different numbers of errors due to the fact that accessibility tools differ in their interpretation of the WCAG, which supports contention [58]. The authors concluded that automated evaluation tools may underestimate or overestimate the number of accessibility errors on a webpage, making the reliability of such tools doubtful.

Choosing website accessibility evaluation tools is not a trivial decision: whether or not to pick the easiest one to use, or the fastest one to learn or the one which produces low false positives. The choice of the tools without previous experience can be a daunting task, especially when working under the pressure of time constraints [59]. Many factors need to be taken into consideration when choosing the suitable evaluation tool. The tool should be clear and user-friendly, provide high quality and reliable results and be capable of testing the browser's DOM in order to test what users are experiencing.
Additionally, the tool must be suitable to integrate in the development process and flexible enough to be used in any environment by any team in any location. While many tools provide some guidance on verifying results which need to be manually checked, few of them provide easy to follow and user-friendly guidance on performing such manual inspection. There are other factors, including but not limited to the ones mentioned above, to consider when choosing the appropriate evaluation tool [60].

\section{2) Users' testing problems}

Although accessibility tools and guidelines can help in detecting accessibility problems, user testing should be applied whenever it is possible to verify the results [61]. User testing is a process where formal or informal experiments are set up with real users who are asked individually to perform goal-free or oriented navigation on a website, and whose behavior is observed by experienced evaluators. Lab studies with real users are the most effective when conducted early in the lifecycle of a product but can also be conducted towards the end of the iterative design cycle (i.e. when large accessibility problems might be ignored to ship a product or release a site on time). Involving users with disabilities in evaluation has many benefits; however, it cannot alone determine if a website is accessible or not [62].

Several studies of usability evaluation methods [63, 38] have shown that user testing methods may fail in yielding consistent results when performed by different evaluators and that an inspection-based method is not shortcoming free. Other difficulties were observed, like preparing testing materials, developing realistic scenarios of tasks and choosing the right sample size for the test [64]. In addition, this kind of testing has been criticized for being subjective and for depending on the users' background as well as the Internet skills. Although accessibility and usability are two different properties, there is no reason to assume that the kind of uncertainty that applies to usability evaluation methods should not apply to accessibility as well.

User testing is a part of usability testing, but user testing with disabled users also adds accessibility findings to the normal usability findings. User testing can be conducted in labs or remotely [65]. In lab testing, a live moderator or observer prepares a scenario and uses a think-aloud technique with high facilitator interaction. Data collection and tasks would focus on specific areas of concern for potential accessibility problems, rather than general site usage. On the other hand, in remote user testing, the tester moderates the test via communication means (e.g. phone, webcam, and web-based tool) rather than being on-site with the user. This is often done due to budget constraints in setting up appropriate labs or when the targeted users are scattered across the country.

Recruiting qualified disabled users is not a trifling task since there is a complexity associated with engaging the right users who match the website audience demographics [66]. People with disabilities are diverse and use different interaction techniques and assistive technology. It is important to recruit people with disabilities, characteristics and expertise depending on the target audience. However, accessibility teams often have limited access during testing phase to real disabled users that 
meet the end-user profile and who can take time out to do the evaluation. Users regularly have inadequate means to attend to the evaluation. The use of varied assistive devices, like screening techniques, may cause further problems during the evaluation, especially due to the fact that the mastery of a particular device does not mean an automatic skills transfer to another or newer device, besides hardware incompatibility [59]. Thus, recruiting users for testing normally requires that the level of technical savvy of the tester is known and documented [12]. Novice moderators with limited experience can get confused by the type of difficulties being faced by users. It is important to differentiate between challenges in dealing with assistive technology (especially when the assistive tool is a different product than the user is familiar with) and challenges being faced with the website being tested.

User testing with small populations often provides useful information, and normally when combined with more qualitative techniques can help to understand users' behaviors. However, it is not statistically robust due to the small participants' numbers [67]. It is hard to draw conclusions from limited studies, and results cannot be generalized to all people with similar disabilities. User testing with special populations can be beyond the expertise or financial resources of a typical web developer and can incur greater time and monetary costs due to special arrangements for testing [66].

It is important to know the type of the adaptive strategies or the assistive technology being used by users to arrange a lab that simulates their real interaction experience. Assistive technologies are software and hardware that people with disabilities use to improve interaction with products. In the case of web accessibility testing, it is preferable to ask user to bring assistive technology they are familiar with to make them feel relaxed. Unfortunately, it is not always the case that users are being able to bring their assistive technologies. Many assistive technologies being used by real users can be very expensive and demo versions are limited which make the cost of preparing appropriate labs high. Time requirement escalates with the need to prepare labs equipped with appropriate assistive tools. This kind of procedure can be beyond the testing cost of the IT team. In some cases, it might be best to go to the user's place, rather than having the user come to labs. A drawback to this is that limited numbers of the project team get direct interaction with the user.

Generally, remote testing is less expensive than a traditional lab testing [68]. Nevertheless, it embeds many challenges like users being unable to share their screen over the Internet or having unreliable or slow connection speeds. Moreover, there is the restriction of the user's body language that might inhibit some of the cues to their reactions to the website being tested.

\section{WEB ACCESSIBILITY CHALLENGES SUMMARY}

After we theoretically analyzed the challenges related to web accessibility, we summarize them in a table format along with their various associated forms. Table II depicts forms and examples for "Standards and Guidelines Challenges", "Challenges during Website's Design and Development" and "Challenges during Evaluation", respectively elicited from the previous literature discussed earlier.
TABLE II. WeB ACCESSIBILITY CHALLENGES SUMMARY

\begin{tabular}{|c|c|}
\hline $\begin{array}{l}\text { Challenge } \\
\text { Forms }\end{array}$ & Examples \\
\hline \multicolumn{2}{|c|}{ Standards and Guidelines Challenges } \\
\hline Ambiguity & $\begin{array}{l}\text { - The WCAG } 2.0 \text { includes some measurements } \\
\text { which need to be quantified in order to be } \\
\text { interpreted in the same way by all web } \\
\text { developers }\end{array}$ \\
\hline $\begin{array}{l}\text { Only English } \\
\text { version is } \\
\text { available }\end{array}$ & $\begin{array}{l}\text { - Inaccessible to developers who do not } \\
\text { understand English Language }\end{array}$ \\
\hline Incompleteness & $\begin{array}{l}\text { The application of WCAG } 2.0 \text { alone is not } \\
\text { sufficient to guarantee website accessibility }\end{array}$ \\
\hline $\begin{array}{l}\text { Hard to } \\
\text { navigate }\end{array}$ & $\begin{array}{l}\text { - The guidelines normally are presented in } \\
\text { descriptive texts, navigation links and tables, } \\
\text { which is not an effective display way for the } \\
\text { designers and developers. }\end{array}$ \\
\hline $\begin{array}{l}\text { Not suitable } \\
\text { for naïve web } \\
\text { developers }\end{array}$ & $\begin{array}{l}\text { Following WCAG } 2.0 \text { requires qualified web } \\
\text { developers with certain level of technical } \\
\text { knowledge of accessibility in order to read and } \\
\text { interpret the guidelines. }\end{array}$ \\
\hline $\begin{array}{l}\text { Requires } \\
\text { perfection }\end{array}$ & $\begin{array}{l}\text { - All the SCs on each level have to be met in } \\
\text { order to get the conformance logo which could } \\
\text { be frustrating to web developers }\end{array}$ \\
\hline Inefficiency & $\begin{array}{l}\text { - Following the guidelines could make the } \\
\text { accessibility evaluation process slow. } \\
\text { Furthermore, even in large companies, } \\
\text { resources including time, money and staff are } \\
\text { hard to allocate for accessibility. }\end{array}$ \\
\hline \multicolumn{2}{|c|}{ Challenges during Website's Design and Development } \\
\hline $\begin{array}{l}\text { Lack of } \\
\text { Accessibility } \\
\text { Awareness }\end{array}$ & $\begin{array}{l}\text { - Despite awareness about accessibility over the } \\
\text { last few years at the levels of government and } \\
\text { legislation, web developers are unaware of the } \\
\text { legal and industry requirements of effective } \\
\text { accessibility and their level of knowledge } \\
\text { remains quite low. } \\
\text { Despite the availability of WAI guidelines } \\
\text { online, most IT professionals are unaware of } \\
\text { them and do not use them. }\end{array}$ \\
\hline $\begin{array}{l}\text { Lack of } \\
\text { Accessibility } \\
\text { Motivation }\end{array}$ & $\begin{array}{l}\text { - Lack of knowledge and motivation by } \\
\text { developers and designers because of the time } \\
\text { consuming accessibility testing process. }\end{array}$ \\
\hline $\begin{array}{l}\text { Untrained IT } \\
\text { Team }\end{array}$ & $\begin{array}{l}\text { - lack of exposure to accessibility during training } \\
\text { courses for Information Systems professionals } \\
\text { - Most web designers and developers have little } \\
\text { experience to ensure that their code attends to } \\
\text { accessibility requirements. }\end{array}$ \\
\hline \multicolumn{2}{|c|}{ Challenges during Evaluation } \\
\hline $\begin{array}{l}\text { Automated } \\
\text { Tools } \\
\text { Problems }\end{array}$ & $\begin{array}{l}\text { - Choosing the right accessibility tool can be time } \\
\text { consuming. } \\
\text { - The need for manual inspection along the tools. } \\
\text { - Some guidelines are not checked properly (e.g. } \\
\text { "alt" attribute). } \\
\text { - Automated tools results are hard to analyze by } \\
\text { inexperienced web developers, which can affect } \\
\text { the quality of the test process. } \\
\text { - Can give inaccurate results and results can vary } \\
\text { from one tool to another, depending on } \\
\text { interpretation of the guidelines. }\end{array}$ \\
\hline $\begin{array}{l}\text { User Based } \\
\text { Testing } \\
\text { Problems }\end{array}$ & $\begin{array}{l}\text { - The cost of setting up labs is quite high. } \\
\text { - User testing with large samples is often beyond } \\
\text { the expertise or financial resources of a typical } \\
\text { web developer and is more time consuming } \\
\text { than other methods. } \\
\text { - Finding disabilities that match the website }\end{array}$ \\
\hline
\end{tabular}




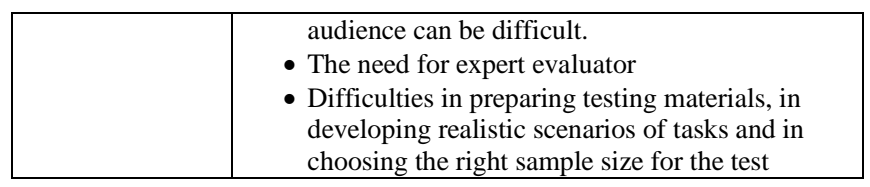

\section{WEB ACCESSIBILITY RECOMMENDATIONS}

Now that we have summarized accessibility challenges, we introduce our recommendations and practical solutions to overcome challenges regarding accessibility guidelines and challenges facing developers during website's design and development as illustrated in Fig. 2.

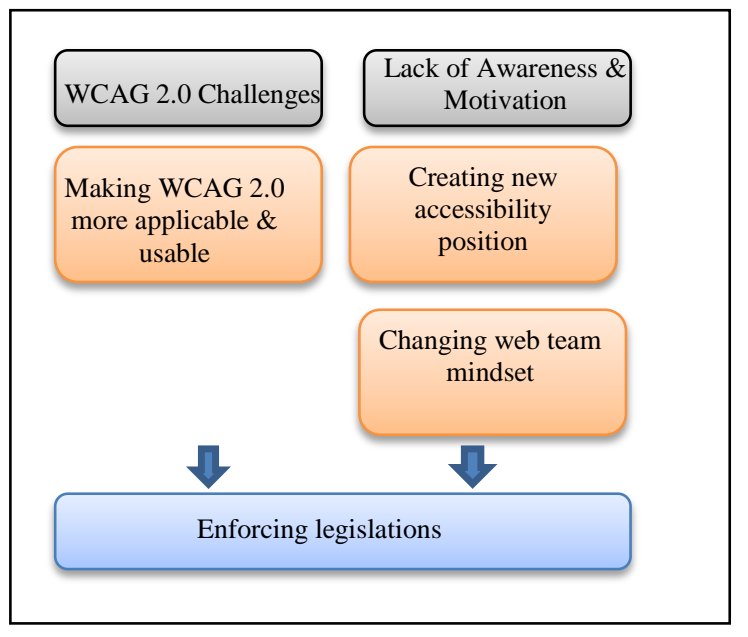

Fig. 2. Suggested solutions to overcome some accessiblity challenges

\section{1) Providing applicable and usable guidelines}

It is not the case that WCAG 2.0 is not good enough; it will be more useful if the WAI structures the guidelines via job roles that each guideline impacts (i.e. SC will be easier to read if each web team member knows which of them he/she needs to deal with). WAI's assignment of levels to WCAG 2.0 SCs considers the needs of disabled users; however, it will be very helpful if they give an idea of the disability type that would benefit from conforming to each criterion. Moreover, WAI has to be transparent regarding the cost of implementing each guideline. Reasonable measures should include identification of the costs of conforming to accessibility guidelines. Instead of emphasizing the need for perfection, guidelines should be flexible enough to encourage web developers to follow them. This, indeed, will contribute to minimizing the difficulty in both guidelines' structure and presentation.

\section{2) Enforcing accessibility legislation}

Widespread recognition of the contribution of ICT, and the web in particular, towards promoting social inclusion and reducing discrimination against people with disabilities is reflected in legislations and policies across the world. Awareness of the nature and implication of legislations and policies regarding web accessibility in different countries is important to guide organizational web accessibility policy. Individual industries and countries need to diligently enhance the enforcement of accessibility legislation. This can be made possible by enacting their own legal standards or legislation rather than following voluntary guidelines.

\section{3) Creating new web accessibility position}

One possible viable solution to increase accessibility motivation is to create a new position related to accessibility, e.g. accessibility specialist/expert. This expert can interact with the project team and senior management to make a positive impact on both the community (potential customers) and the organization. In fact, this expert can be a web developer, a quality assurance engineer, or a project manager who takes accessibility training courses and participates in workshops. On the other hand, organizations should start sponsoring workshops for their employees and allocate appropriate funding to support accessibility in their reserved budget.

\section{4) Changing the web team mind-set}

To meet end-users' needs, web developers are required to feel as end-users in the accessibility issue. In other words, programmers have to test the website with disabled people or at least use a standardized accessibility testing tool, so that when web developers want to write/change the website's source code, there is a need to change the developers' mind-set to include accessibility. Many web developers do not know the importance of making a website accessible and how this will help disabled people to interact with the web. Moreover, we must change the programmer's perspective regarding the way they code rather than simply asking for a list of changes. Thus, there is a real need to move away from a problem-based approach towards a design principle approach for web accessibility. The whole web team should be inclusive from the beginning when designing an accessible website. Private and public sectors should stress that accessibility is an important indicator of website quality and, without it; the quality of the website will remain low. In addition, emphasizing the importance of accessibility guidelines should start early in web development education. This should take place at the entry level of web development courses. Training and exposing IT professionals and web engineers to accessibility guidelines at an early stage increases their awareness and improves their (programming) attitudes toward this vital issue. Why wait to expose IT students to accessibility until they take senior computing courses when we can make them aware of it earlier? By making accessibility the focus of an introductory level computer science course, we can increase accessibility awareness among IT students.

\section{CONCLUSION}

Web accessibility is one of the most crucial issues facing the online community. There are various challenges related to websites accessibility that face disabled users and which limit their utilization of the website and may therefore impact their equal rights as well as the organization's revenues. This article has reviewed the negative impact of web accessibility challenges and has critically discussed the primary problems associated with each challenge. Standards and guidelines, during website's design and development (user's awareness, motivation and training) and during-evaluation (automated tools and user testing) have been identified as the three main challenges. Furthermore, we discussed each challenge main problems and their impact on web accessibility. Finally, a list of recommendations was proposed to overcome these challenges. A total collaboration between web team, stakeholders, individual industries and countries is essential to ensure equality and human rights in using the web without 
illegal discrimination. We argue that simplifying guidelines and making them more applicable will encourage web developers to follow them. Moreover, we suggest the need for accessibility legislation enforcement by countries rather than following voluntary guidelines. In addition, a project manager has the responsibility to make his web team adhere to accessibility principles. Without a managerial impact on accessibility, it is quite normal for the web team to ignore the accessibility issue or to pretend they have taken care of it. We also need to train and change the web team mind-set regarding how they code to take into consideration the accessibility issue when they program.

\section{REFERENCES}

[1] A. Martínez, J. De Andrés, and J. García, "Determinants of the web accessibility of European banks", Information Processing \& Management, Vol. 50 No. 1, pp. 69-86, 2014.

[2] W3C, "Introduction to web accessibility", available from: http://www.w3.org/WAI/intro/accessibility.php (accessed 2 January 2016)

[3] B. Hashemian,"Analyzing web accessibility in Finnish higher education", in Proceedings of the 13th international ACM Sigaccess Conference on Computers and accessibility (Assets '11), ACM Press, New York, NY, Vol. 101, pp. 8-16, 2011.

[4] K. Nahon, I. Benbasat, and C. Grange, "The missing link: intention to produce online content accessible to people with disabilities by nonprofessionals", in proceeding of 2012 45th Hawaii International Conference on System Sciences (HICSS), IEEE Computer Society, Washington, DC, pp. 1747-1757, 2012.

[5] S. Trewin, B. Cragun, C. Swart, J. Brezin, and J. Richards, "Accessibility challenges and tool features: an IBM web developer perspective", in Proceedings of 2010 International Cross Disciplinary Conference on Web Accessibility (W4A '10), ACM Press, New York, NY, pp. 32:1-32:10, 2010

[6] C. Avila, S. Baldiris, R. Fabregat, and J. Guevara, "Accessibility evaluation improvement using case based reasoning", Frontiers in Education Conference (FIE), Seattle, Washington, pp.1-6, 2012.

[7] C. Power, A. Freire, H. Petrie, and D. Swallow, "Guidelines are only half of the story: accessibility problems encountered by blind users on the web", in Proceedings of the SIGCHI Conference on Human Factors in Computing Systems (CHI '12), ACM Press, New York, NY, pp.433442, 2012

[8] J. Brown, and H. Scott, "The challenges of web accessibility: the technical and social aspects of a truly universal web", First Monday, Vol. 20 No. 9, 2015.

[9] J. López, A. Pascual, L. Masip, T. Granollers, and X. Cardet, "Influence of web content management systems in web content accessibility", in Proceedings of the 13th IFIP TC 13 international conference on Humancomputer interaction (INTERACT'11), P. Campos et al. (Eds.), pp. 548-551, 2011.

[10] M. Baowaly, and M. Bhuiyan, "Accessibility analysis and evaluation of bangladesh government websites", Computer Engineering and Intelligent Systems, Vol. 3 No.4, pp. 46-51, 2012.

[11] T. Vu, D. Tuan, and V. Phan, "Checking and correcting the source code of web pages for accessibility", in proceeding of 2012 IEEE RIVF International Conference on Computing and Communication Technologies, Research, Innovation, and Vision for the Future (RIVF), IEEE Computer Society, Washington, DC, pp.1-4, 2012.

[12] G. Brajnik, Y. Yesilada, and S. Harper, "The expertise effect on web accessibility evaluation methods", Human-Computer Interaction, Vol.26 No. 3, pp. 246-283, 2011.

[13] S.R. Vázquez, "Introducing web accessibility to localization students: implications for a universal web", in Proceedings of the 16th international ACM SIGACCESS conference on Computers \& accessibility (Assets '14), ACM Press, New York, NY, pp. 333-334, 2014.
[14] A. Olalere, and J. Lazar, “Accessibility of U.S. federal government home pages: section 508 compliance and site accessibility statements", Government Information Quarterly, Vol. 28 No. 3, pp.303-309, 2011.

[15] A.A. Nizar, A. Obedidat, and H.Y. Abu-Addose, "Accessibility as an indicator of Jordanian e-government website quality", in Proceedings of 2013 Fourth International Conference on e-Learning Best Practices in Management, Design and Development of eCourses: Standards of Excellence and Creativity, IEEE Computer Society, Washington, DC, pp. 156-160, 2013.

[16] S. Lujan-Mora, R. Navarrete, and M. Penafiel, "E-government and web accessibility in South America", in Proceedings of 2014 First International Conference on eDemocracy and eGovernment (ICEDEG), IEEE Computer Society, Washington, DC, pp. 77-82. R. Nicole, "Title of paper with only first word capitalized," J. Name Stand. Abbrev., in press, 2014.

[17] Y. Akgül, and K. Vatansever, "Web accessibility evaluation of government websites for people with disabilities in Turkey", Journal of Advanced Management Science, Vol.4 No. 3, pp. 201-210, 2016.

[18] S. Harper, Y. Yesilada, and S. Abou-Zahra, Web accessibility evaluation, Springer, London, pp. 79-106, 2008.

[19] L. Kubitschke, K. Cullen, C. Dolphin, S. Laurin, A. Cederbom, J. Usero, ...F. Nu., "Study on assessing and promoting e-accessibility", European Commission, Brussels, available from: https://ec.europa.eu/digital-single-market/en/news/study-assessing-andpromoting-e-accessibility,2013.

[20] Internet Society, "Internet accessibility: internet use by persons with disabilities: moving forwards", available from: http://www.internetsociety.org/,2012.

[21] D. Sloan, and S. Horton, "Global considerations in creating an organizational web accessibility policy", in Proceeding of the 11th Web for All Conference (W4A '14), ACM Press, New York, NY, pp.16, 2014.

[22] WCAG, available from: http://www.w3.org/WAI/intro/wcag , 2016.

[23] L. Santarosa, D. Conforto, and R. Machado, "Whiteboard: synchronism, accessibility, protagonism and collective authorship for human diversity on web 2.0", Computers in Human Behavior, Vol. 31, pp.591-601, 2014.

[24] J. Villena, B. Ramos, R.P.M. Fortes, and R. Goulartea, R, "Web videos - concerns about accessibility based on user centered design", Elsevier Procedia Computer Science, Vol. 27, pp. 481-490, 2014.

[25] S. Gordon, S. and S. Lujan-Mora, "Accessible blended learning for nonnative speakers using MOOCs", Interactive Collaborative and Blended Learning (ICBL 2015), IEEE Computer Society, Washington, DC, pp. 19-24, 2015

[26] J.L. Medina, M. I. Cagnin, and D.M.B. Paiva, "Investigating accessibility on web-based maps", ACM SIGAPP Applied Computing Review, Vol. 15 No. 2, pp. 17-26, 2015.

[27] W3C, "About W3C", available from: http://www.w3.org/Consortium/,2016.

[28] WAI,"WAI guidelines and techniques", available from: http://www.w3.org/WAI/guid-tech.html , 2016.

[29] WCAG 2.0.,"Web content accessibility guidelines (wcag) overview", available from: http://www.w3.org/TR/WCAG20/, 2016.

[30] M. Cooper, D. Sloan, B. Kelly, and S. Lewthwaite, "A challenge to web accessibility metrics and guidelines: putting people and processes first", in Proceedings of the International Cross-Disciplinary Conference on Web Accessibility (W4A '12), ACM Press, New York, NY, pp20, 2012.

[31] G. Miller, S. and Fels, "OpenVL: a task-based abstraction for developerfriendly computer vision", in Proceedings of 2013 IEEE Workshop on Applications of Computer Vision (WACV '13), IEEE Computer Society, Washington, DC, pp. 288-295, 2013.

[32] T. Bittar, L. Amaral, F. Faria, and R.P.M. Fortes, "Supporting the developer in an accessible edition of web communications: a study of five desktop tools", in Proceedings of the Workshop on Information Systems and Design of Communication (ISDOC '12- EuroSIGDOC), ACM Press, New York, NY, pp.3-9, 2012.

[33] V. Conway, Website accessibility in Australia and the Australian government's national transition strategy: outcomes and findings, Ph.D. thesis, Western Australia: Edith Cowan University, 2014. 
[34] F. Alonso, L. Fuertes, L. González, and L. Martíez, "On the testability of wcag 2.0 for beginners", in 7th International Cross-Disciplinary Conference on Web Accessibility (W4A'10), ACM Press, New York, NY,pp.1-9,2010.

[35] E. Tanaka, and H. da Rocha, "Evaluation of Web Accessibility Tools", in Proceedings of the 10th Brazilian Symposium on on Human Factors in Computing Systems and the 5th Latin American Conference on Human-Computer Interaction (IHC+CLIHC '11), Brazilian Computer Society, Porto Alegre, Brazil, pp. 272-279, 2011.

[36] C. Loitsch, A. Stiegler, C. Strobbe, D. Tzovaras, K. Votis, G. Weber, and G. Zimmermann, "Improving accessibility by matching user needs and preferences", Assistive Technology: From Research to Practice. In Proceedings of AAATE2013, IOS Press, Vilamoura, Portugal, Vol. 33, pp. 1357-1365, 2013.

[37] H. Petrie, C. Power, D. Swallow, C.A. Velasco, B. Gallagher, M. Magennis, ...K. Down,"The value chain of web accessibility: challenges and opportunities", in Proceedings of the Workshop on Accessible Design in the Digital World 2011, CEUR Workshop Proceedings, Lisbon,Portugal,pp.2-12,2011.

[38] G. Brajnik, Y. Yesilada, and S. Harper, "Testability and validity of wcag 2.0: the expertise effect", in Twelfth International ACM SIGACCESS Conference on Computers and Accessibility (Assets' 10). Orlando, FL: ACM Press, New York, NY, USA. p. 43-50, 2010.

[39] Hassell Inclusion, "The future of wcag - maximizing its strengths not its weaknesses", $\quad$ available from: http://www.hassellinclusion.com/2013/01/wcag-future/, 2013.

[40] L. Pereira, S. Ferreiraa, H. Bragaa, L. Cardoso, D. Salgadob, and R Nunes,"Using cultural viewpoint metaphors to provide web accessibility for the visually impaired users", Elsevier Procedia Computer Science, Vol. 27, pp. 186-196, 2014.

[41] Y. Yi, and J. Kang, "Do public library websites consider the disabled or senior citizens?", in Proceedings of the 12th ACM/IEEE-CS joint conference on Digital Libraries (JCDL '12), ACM Press, New York, NY,pp.373-374,2012.

[42] J.T. Nganji, M. Brayshaw, and B. Tompsett, "Describing and assessing image descriptions for visually impaired web users with idat", in 3rd International Conference on Intelligent Human Computer Interaction. Springer-Verlag, Lecture Notes in Computer Science, August 2011, Reprinted in Advances in Intelligent Systems and Computing, Springer Verlag, Vol. 179, pp. 27-37, 2013.

[43] S.R. Pye, Web Accessibility and its Future: The Requirement of Awareness and Enforcement of Accessibility for those with Visual Disabilities, Graduation Project, Norwich, UK, University of East Anglia, 2011.

[44] TAW Tool, available from: http://www.tawdis.net/, 2016.

[45] M. Rosson, J. Ballin, J. Rode, and B. Toward, "Designing for the web: revisited: a survey of informal and experienced web developers", ICWE'05 Proceedings of the 5th international conference on Web Engineering. Sydney, ACM Press, New York, NY, pp.522-532, 2005.

[46] S. Gordon, S. and Lujan-Mora, "Web accessibility of moocs for elderly students", 12th International Conference on Information Technology Based Higher Education and Training (ITHET 2013), Antalya, Turkey, pp. 1-6, 2013.

[47] J. Lazar, B. Wentz, A. Almalhem, A. Catinella, C. Antonescu, Y. Aynbinder, ...M. Seidel, "A longitudinal study of state government homepage accessibility in maryland and the role of web page templates for improving accessibility", Government Information Quarterly, Vol. 30 No.3, pp. 289-299, 2013

[48] S. Krug, A common sense approach to web usability, (2nd ed.), New Riders Publishing, Berkeley, California, 2014.

[49] R. Lopes, K. Isacker, and L. Carricco,"Redefining assumptions: accessibility and its stakeholders", in Proceedings of the 12th international conference on Computers helping people with special needs: Part I (ICCHP'10). Klaus Miesenberger, Joachim Klaus, Wolfgang Zagler, and Arthur Karshmer (Eds.), Springer-Verlag, Berlin, Heidelberg,pp.561-568,2010.
[50] A.P. Freire, C.M. Russo, and R.P.M. Fortes, "A survey on the accessibility awareness of people involved in web development projects in Brazil", in Proceedings of 2008 international cross-disciplinary Conference on Web Accessibility (W4A'08), ACM Press, New York, NY pp.87-96, 2008.

[51] G. Brajnik, and S. Harper, "Model-based engineering of user interfaces to support cognitive load estimation in automotive applications", in Cognitive Load and In-Vehicle Human-Machine Interaction Workshop; adjunct Proceedings of the 5th Int. Conference on Automotive User Interfaces and Interactive Vehicular Applications. Kun, A., Froelich, P. (eds.), Eindhoven, ACM Press, New York, NY, 2013.

[52] R. Gonçalves, J. Martins, and F. Branco, "A review on the Portuguese enterprises web accessibility levels - a website accessibility high level improvement proposal", Elsevier Procedia Computer Science, Vol. 27, pp.176-185, 2014.

[53] A-Checker Tool, available from: http://achecker.ca/checker/index.php, 2016.

[54] WAVE Tool, available from: http://wave.webaim.org/, 2016.

[55] K. Johari, and A. Kaur, "Measuring web accessibility for persons with disabilities", in Proceedings of 2012 Fourth International Conference on Computational Intelligence and Communication Networks (CICN '12), IEEE Computer Society, Washington, DC, pp.963-967,2012.

[56] R. Lopes, D. Gomes, D. and L. Carriço, "Web not for all: a large scale study of web accessibility", in Proceedings of 2010 International Cross Disciplinary Conference on Web Accessibility (W4A '10), ACM Press, New York, NY, pp.10:1-10:4, 2010.

[57] H. Abuaddous, M.Z. Jali, and N. Basir,"Study of the accessibility diagnosis on the public higher institutions websites in Malaysia", in Proceedings of the 4th International Conference on Computing and Informatics (ICOCI 2013), Sarawak, Malaysia, Universiti Utara, pp. 122-127, 2013.

[58] H. Al-Khalifa, "WCAG 2.0 semi-automatic accessibility evaluation system: design and implementation", Computer and Information Science, Canadian Center of Science and Education, Vol. 5 No.6, pp.7387, 2012.

[59] M. Greeff, and P. Kotzé, "A lightweight methodology to improve web accessibility", in Proceedings of 2009 Annual Research Conference of the South African Institute of Computer Scientists and Information Technologists (SAICSIT '09), ACM Press, New York, NY, pp.30-39, 2009.

[60] K. Groves, "A Challenge to Accessibility Testing Tool Vendors", available from: http://www.karlgroves.com/2012/10/03/a-challenge-toaccessibility-testing-tool-vendors/, 2013

[61] M.F. Theofanos, and J.G. Redish, "Bridging the gap: between accessibility and usability", Interactions, Vol. 10 No. 6, pp. 36-51, 2003.

[62] S. Horton, S. and M. Quesenbery, A web for everyone: designing accessible user experience, Rosenfeld Media, 2014.

[63] J. Nielsen, "Why you only need to test with 5 users", available from: https://www.nngroup.com/articles/why-you-only-need-to-test-with-5users/ , 2000.

[64] S.L Henry, "Just ask: integrating accessibility throughout design", available from: www.uiAccess.com/JustAsk/, 2007.

[65] K. Madathil, and J. Greenstein, "Synchronous remote usability testing: a new approach facilitated by virtual worlds", in Proceedings of the SIGCHI Conference on Human Factors in Computing Systems (CHI '11), ACM Press, New York, NY, pp.2225-2234, 2011.

[66] J. Nielsen, "How many test users in a usability study?", available from: http://www.nngroup.com/articles/how-many-test-users/, 2012.

[67] W3C, "Involving users in evaluating web accessibility", available from: http://www.w3.org/WAI/eval/users.html , 2010.

[68] A. Bruun, and J. Stage, "The effect of task assignments and instruction types on remote asynchronous usability testing", in Proceedings of the SIGCHI Conference on Human Factors in Computing Systems (CHI '12), ACM Press, New York, NY, pp. 2117-2126, 2012. 